\title{
Power quality issues: Power supply interruptions as key constraint to development in Ekiti State, Nigeria
}

\author{
Adeoye OS * \\ Department of Electrical and Electronic Engineering Federal Polytechnic, Ado-Ekiti. Nigeria.
}

Global Journal of Engineering and Technology Advances, 2021, 07(03), 109-117

Publication history: Received on 01 March 2021; revised on 30 April 2021; accepted on 03 May 2021

Article DOI: https://doi.org/10.30574/gjeta.2021.7.3.0052

\begin{abstract}
The power quality issues in the world today are critical to the development of different nations. Prosperity of each nation depends on availability of constant power supply and the quality of supply of power is very important to the required developments in world in the past, the present and the future. Constant power supply is a major challenge in Africa particularly in Nigeria where the generated power is less than thirty percent of the required power. The metrics of power quality are voltage sag, flickers, spikes, harmonics, notching, transients and interruptions. This paper reviewed power quality issues and the interruptions as they affect the development of the State. The level of interruptions in Ekiti State was thoroughly examined and the causes of power interruption in the State were investigated. The method used was the collection of data in respect of power interruptions on Ekiti feeders from the Benin distribution company, assessment of the collected data through simple programming as a command for plotting the graphs through the use of MATLAB 2015 depicting the behavioural pattern of the interruption for a period of six months in 2016 . The result shows that the interrelationship between the interruptions and development particularly as it affects domestic consumers, small and medium scale enterprise adversely. Recommendations were suggested with the objective of solving the problems being set up by interruptions in the State and these include installation of reactors, automatic voltage regulators and effective tap changing system on the lines, busses and transformer substation respectively.
\end{abstract}

Keywords: Development; Feeder; Interruption; Power; Quality

\section{Introduction}

The prosperity of a nation is the function of the annual per capita consumption of electrical energy. The United States has only $6 \%$ of the world population but accounts for over $30 \%$ of electrical consumption of the world [1]. Ekiti is an agrarian State located in the eastern part of south western Nigeria, a typical rainforest belt. The State is bounded in the north by Kogi and Kwara; to the south and east by Ondo while in the west, it is bounded by Osun State. The State is located within the tropics between latitudes 70151 to 8051 north of equator and longitudes of 40451 to 50451 east of prime meridian [2]. The power grid is mentioned in the latitudes and longitudes with 16 local government areas of a land mass of $5887.89 \mathrm{~km} 2$ [3]. Electricity in the State is sporadic, erratic and could be classified as the worst in the civilised world. The power line winds its way through $268 \mathrm{~km}$ of roads, probably the longest of such in the world. The State has over one hundred towns and villages with electricity served with $33 \mathrm{kV}$ lines [4]. The power supply sources to Ekiti State are Omu-aran, Isanle Mokutu, Akure and Ilesa with $12.7 \mathrm{MW}, 4 \mathrm{MW}, 10.8 \mathrm{MW}$ and $10 \mathrm{MW}$ respectively [5]. Power quality (PQ) is concerned with deviation of voltage and frequency from ideal. The quality of power delivered to Nigerian populace is characterised by cases of voltage fluctuations, harmonics, voltage dip, supply interruptions, transients, spikes, voltage imbalances e.t.c. These problems need to be addressed to ensure safe, reliable and the right quality of electricity services [6] Other PQ issues are brownouts, blackouts, notching, harmonic resonance, noise, impulse, ground noise, common mode noise, critical load, crest factor, voltage variation, transient, dirt power, over-

\footnotetext{
${ }^{*}$ Corresponding author: Adeoye OS

Department of Electrical and Electronic Engineering Federal Polytechnic, Ado-Ekiti. 
voltage, under-voltage, ground loops, raw power, blink, voltage regulation, oscillatory transient and electromagnetic compatibility [7, 8]. Interruption is defined as the complete loss of supply voltage or load current. It is the duration of interruption that categorise it into instantaneous, momentary, temporary or sustained form. The duration for instantaneous, momentary, temporary and sustained interruption are 0.5 to 30 cycles, 30 cycles to 2 seconds, 2 seconds to 2 minutes and greater than 2 minutes respectively[9]. In the same vein, interruption is a complete loss of voltage in one or more phases [10]. Sustained interruption describes a situation in commercial utility system where automatic protective devices are used because of the nature of fault cannot bring power back online and manual intervention is required. The terminology accurately describes the situation more than commonly used term 'outage'. The term outage actually refers to the state of a component in the system that has failed to function as expected. It is safe to say that one has a sustained interruption if the power has been off for more than two minutes and the utility trucks may appear shortly after to repair utility lines outside [11]. The causes of interruptions are: loss of supply; tree contacts; lightning; adverse weather; foreign interference and defective equipment. The knowledge of economic impact of electricity supply disruptions is important for regulators and policy makers, given the extensive interdependencies between the power sector and other infrastructure industries [12]. There are four categories of interdependency such as geographical, logical, cyber and physical $[13,14]$. There are two main approaches to estimating the cost of energy not supplied. These are willingness to pay (WTP) for reliable services or willingness to accept (WTA) interruptions used in estimation of cost of electrical energy for consumers. The second approach is based on production functions with the value of output of firms or the time spent on non-paid work in the case of households [15]. In some countries all over the world, when the need to interrupt power supply arises, the power authority usually issue notice. However, this was not in practice in Nigeria due to lack of competitiveness among the distribution companies. Lately, the power authorities have started to issue notices of power interruption based on the rights of customers as indicated in the customers' obligation rights and endless pressures mounted on the distribution companies by customers. Tables 1 and 2 show the characteristics of categories of interruption and power disturbance classification to EN 50160. Therefore, a legal frame work should be put in place by constitution to support the consumers of energy in Nigeria.

\section{Review of Literature of Power Quality Issues}

The changes in electric power system are related to the changes in the society. The development in the society and the grid cannot be achieved unless there is an immense impact on the electricity generation, the distribution, and the utilization of electrical energy by the consumers. The changes that can positively have impact on the grid and the society are changes in production; utilization changes and the changes in the grid. For changes in production, the injection of smaller units being connected to the distribution network rather the connection of conventional large production unit under the control of a network operator. The new utilization methods are electric vehicles; adjustable speed drives in place of direct driven electric motors, compact fluorescent, light emitting diode lamps in place of incandescent lamps and injection of renewable energy sources that generates power quality indices along the distribution networks [16]. Recent injection of renewable energy sources (RES) and power electronic devices also known as non linear loads into the existing grid network have resulted into continuous production of power quality (PQ) issues such as voltage sags, voltage swells, spikes, harmonics, power interruptions, inter-harmonics, supra-harmonics, slow voltage variations, fast voltage variations, voltage unbalance, transients, frequency variations among others $[17,18]$. $P Q$ is the result of both voltage and current quality and is caused by the deviation of either voltage or current from its ideal [19].

\subsection{Voltage sags}

They are the reduction in the root means square voltage by at least $10 \%$ of the nominal voltage for a period of half a cycle and a minute. IEEE1159 classifies voltage sags into instantaneous, momentary and temporary with 0.5 cycles to 30 cycles, 30 cycles to 3 seconds and greater than 3 seconds to 1 minute respectively. Switching on of a large motor, introduction of faults into the grid are the causes of voltage sags and voltage variation of root mean square such as voltage sags, swells, under-voltages, over-voltages and interruptions can be mitigated by the use of un-interruptible power supplies. Voltage sags can also be addressed by constant voltage transformers [20].

\subsection{Harmonics}

They are periodic sinusoidal distortions of the supply voltage and load current caused by non-linear loads. The sources of harmonics are rectifiers, motor drives, microprocessors, data processing equipment, high efficiency lighting, switched mode power supplies, welding machines, arc furnaces, fluorescent lights, d.c brush motors and any electric loads. Harmonics have frequencies that are integer multiples of the waveform's fundamental frequency. A given $50 \mathrm{~Hz}$ fundamental waveform, the 2nd, 3rd, 4th, 5th , 6th, 7 th harmonic components are $100 \mathrm{~Hz}, 150 \mathrm{~Hz}, 200 \mathrm{~Hz}, 250 \mathrm{~Hz}, 300 \mathrm{~Hz}$ and $350 \mathrm{~Hz}$ respectively. Therefore, harmonic distortion is the degree to which a waveform deviates from its pure sinusoidal values as a result of the summation of all these harmonic elements. The ideal sine wave has zero harmonic components which mean there is nothing to distort the perfect wave. Total harmonic distortion is the degree of 
measurement of harmonic distortion present and is defined as the ratio of the summation of all harmonic components of the voltage or current wave. Mitigation of PQ problems is through load conditioning by making equipment less sensitive to power disturbances. Power filters and hybrid filters are most effective mitigation devices for PQ issues [21].

\section{Interruption of power supply}

It is experienced when the line voltage reduces to less than 0.1 p.u for a period not longer than 60 seconds. When the period of interruption is more than $60 \mathrm{~s}$, it is called sustained interruption. The causes of interruption are insulation failure, faulty grounding, lightning and flashover. Interruption leads to opening and closure of protective devices to isolate faulty section of the system automatically [22].

\subsection{Indices of long term and short term interruptions and sags}

Long term sustained interruption measurements are known as reliability indices. Sometimes, each utility may have a long variation in the minimum interruption time that is looked at by the reliability indices that are used; the general idea is that these are events where voltage has dropped to zero for 1-5 minutes. The indices to measure long term interruption are: System Average Interruption Duration Index (SAIDI) which is defined as the net total time per year that the average customer is without power, counting only the sustained interruptions [23]. Equations (1)-(4) are the indices of long and short term interruptions.

SAIDI $=\frac{\text { Total of All Customer Interruption Durations (Sustained) }}{\text { Total Number of Customers Served }}$

System Average Interruption Frequency Index (SAIFI) is the number of times per year that the average customer sees a sustained interruption.

$\mathrm{SAIFI}=\frac{\text { Total } \text { Number } \text { of Customer Interruptions (Sustained) }}{\text { Total } \text { (Sumber of Customers Served }}$

Customer Average Interruption Frequency Index (CAIFI) is the average time of a sustained interruption, that is, the repair time for sustained interruptions.

Average Service Availability (ASAI) is the per unit availability of the power system. This is a positive spin to SAIDI. The total number of hours in a year that power system is made available to the average customer divided by the total hours in the year.

$\mathrm{CAIDI}=\frac{\text { Total of } \text { All Customer } \text { Interruption Durations (Sustained) }}{\text { Total Number of Customer Interruptions (Sustained) }}$

\section{Less Common Interruption Measurements have under-listed measures}

CTAIDI is similar to CAIDI but the denominator counts customers with multiple interruptions only once.CAIFI is the total number of customers interrupted per number of customers interrupted once or more. This is a measure whereby any time someone is interrupted at a time, the question of the net hours of interruption may come into play.

CEMIN is the total number of customers that experience more than $\mathrm{N}$ sustained interruption per total number of customers served. It is similar to CAIDI but the denominator counts customers with multiple interruptions only once.

Momentary Interruptions are defined as interruptions with less than long term interruption and of course are more defined by classifications:

\subsection{Voltage level}

- Interruption: Voltage less than 0.1p.u.

- Sag: Voltage of $0.1-0.9$ p.u

- Swell: Voltage greater than 1.1-1.4p.u.

- Undervolatge: Voltage less than 0.8-0.9p.u.

- Overvoltage: Voltage of 1.1-1.2 p.u. 


\subsection{Time Frame of Interruptions}

- Instantaneous of $0.5-30$ cycles.

- Momentary of 30 cycles -3 seconds.

- Temporary of $3 \mathrm{~s}-1$ minute.

- Long term of greater than 1 minute.

Customers and average customer see any interruption. The number is usually between 10-15 for all interruptions and 10 excluding major storm.

MAIFI $=\frac{\text { Sum of All Customer Interruptions (Momentary Variety }}{\text { Total Number of Customers Served }}$

Customers Interruption Cost are the costs that customers incur because of electric supply disruptions. CICs do not include costs that first incurred by a supplier before being passed through to customers. As long as electricity supply is not disrupted, electric energy remains a commodity product and its value contribution to customer's own value creating processes and activities is a function of the nature of those activities and is independent of the source of the energy. The electric energy generated and transmitted to the grid are undistinguishable to customers and must therefore compete on price alone [24]. Interruption costs can be determined based on the sum total of the value of the lost production and outage related costs as well as subtraction of outage related savings. The value of lost production is equal to the customer's expected revenue without the outage [25].

Table 1 Characteristics of categories of interruption

\begin{tabular}{|l|l|l|}
\hline Category of interruption & Causes & Impacts \\
\hline Short & Power system faults & Loss of supply to customer and equipment \\
\hline Long & Equipment failures & Computer shutdowns \\
\hline & Control Malfunctions & Motor trippings \\
\hline & Cicuit Breaker trippings & \\
\hline
\end{tabular}

Table 2 Power system disturbance classification to EN 50160

\begin{tabular}{|l|l|l|l|l|}
\hline Type of disturbance & Voltage level & Limits from EN 50160 & Measurement Period & Typical Duration \\
\hline Short interruption & & $>99 \%$ & $20-200 /$ day & Up to 3 minutes \\
\hline Long interruption & $230 \mathrm{~V}$ & $99 \% \quad$ Source: [26] & $10-50 /$ day & $>3$ minutes \\
\hline
\end{tabular}

\section{Methodology}

Relevant papers on power quality issues and power supply interruptions were adequately reviewed as the foundation to the paper. Power interruption data were collected from Benin Electricity Distribution Company, Ado- Electricity business unit. These include the over current, earth-fault, permit and load-shedding data for six months ranging from January to June, 2016. A program was written to analyse the level of interruptions, the average and total interruption. MATLAB 2015 was used to plot the graph showing the behavioural pattern. The program was written by MATLAB 2015 as follows:

\%Writing to analyses the power interruption for 6 months in Ekiti Feeders

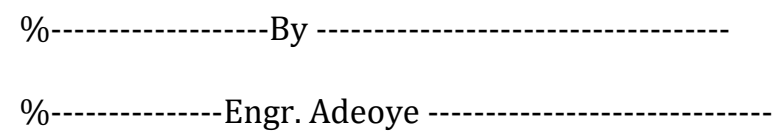

\%School: Federal Polytechnic Ado Ekiti, Ekiti State Nigeria 
\%-------Department: Electrical / Electronic Department------

$\%$

\%INTERRUPTION ON 33KV FEEDERS JANUARY 2016

$\mathrm{x}=[1: 1: 7] ; \% \mathrm{X}$ axis range which is the feeder is range of 1 to 10 with interval 1

subplot $(2,1,1)$;

figure (1);

$y=[10: 10: 500] ; \% y$ axis is range of 10 to 500 interval of 10

over_current_jan $=[0,0,0,0,0,0,0] ; \%$ over current

earth_fault_jan $=[0,105,87,98,0,20,0] ; \%$ earth fault

permit_jan $=[0,0,0,0,3,0,0] ; \%$ permit

load_shelding_jan $=[49,99,134,114,430,480,492] ; \%$ load shelding

total_fault_jan $=[79,170,186,319,373,431,476] ; \%$ overcurrent $(\mathrm{hrs})$

$\%$ fist plot

Plot (x,over_current_jan,'ro-'); \% x again overcurrent

names = \{'Ado/Ado 33KV'; 'Iworoko 33KV'; 'Ikere 33KV'; 'Aramoko/Ilawe';'Agric Olope';'Ise/Emure'; 'Igede';\};

set(gca,'xtick',[1:7],'xticklabel',names)

hold on;

$\%$ second plot

plot(x,earth_fault_jan,'g*-'); \%plot x against earth_fault

hold off;

hold on;

\%third plot

plot(x,permit_jan,'b+-'); \%plot x against permit

hold off;

hold on;

$\%$ fourth plot

plot(x,load_shelding_jan,'md-'); \%plot x against load shelding

\%legend('load_shelding');

hold off; 
hold on;

\%fifth plot

plot(x,total_fault_jan,'ch-'); \%plot x against load shelding

hold off;

legend('Over Current(hrs)','Earthfault (hr)','Permit(hr)','Load Shelding(hr)',('Total Fault(hrs)'));

xlabel('Feeders');

ylabel('Type of Outages');

The same progam is repeated for other months from February to June, 2016.

\section{Discussion}

The interruptions on Ekiti $33 \mathrm{kV}$ feeders are classified into over-current, earth fault, permit, load-shedding and total outages. The plots in fig.1, fig.2, fig.3, fig.4, fig.5 and fig.6 show the outages against the feeders in the months of January, February, March, April, May and June respectively in 2016. The feeders in the network are: Ado/Ado, Iworoko, Ikere, Agric Olope, Ise/Emure, and Igede. In January, 2016, earth fault was at the minimum, at Ado/Ado feeder, Agric Olope, Ise/Emure and Igede feeders. Load shedding was peaked at Agric Olope, Ise/Emure, and Igede feeders while there was a gradual increase from Ado/Ado feeder to Aramoko / Ilawe feeder. The total interruption was of increased gradually from Ado / Ado feeder to Iworoko feeder to Ikere feeder to Aramoko/ Ilawe feeder to Agric Olope feeder to Ise/Emure feeder to Igede feeder. For the month of February, 2016, load shedding was minimum at Ado/Ado feeder but maximum at both Agric Olope and Ise/Emure feeders. Earth fault was minimum at Ado/Ado feeder, Agric Olope and Igede feeders. For March, 2016, load shedding was minimum at Ado/Ado feeder, increased gradually or uniformly at Ikere and Aramoko feeders while it reaches the peak at Agric Olope and Ise / Emure feeders. In April, 2016, load-shedding increased gradually from Ado/Ado feeder through Ise/Emure and Igede feeders. In all cases, the effect of permit was insignificant. In May, 2016, load shedding was greater in all the feeders but it increased from Aramoko feeder through Agric Olope feeder to Ise / Emure feeder. Permit was minimum at Ado/Ado feeder and Agric Olope feeder. In June, 2016, earth fault was minimum at Ado/Ado feeder and Agric Olope feeder. Load shedding was minimum at Aramoko/ Ilawe feeder, peaked at Agric Olope feeder. Total faults increased gradually from one feeder to another, that is, Ado/Ado feeder through Iworoko, Ikere, Aramoko, Agric Olope, Ise/Emure and Igede feeders.
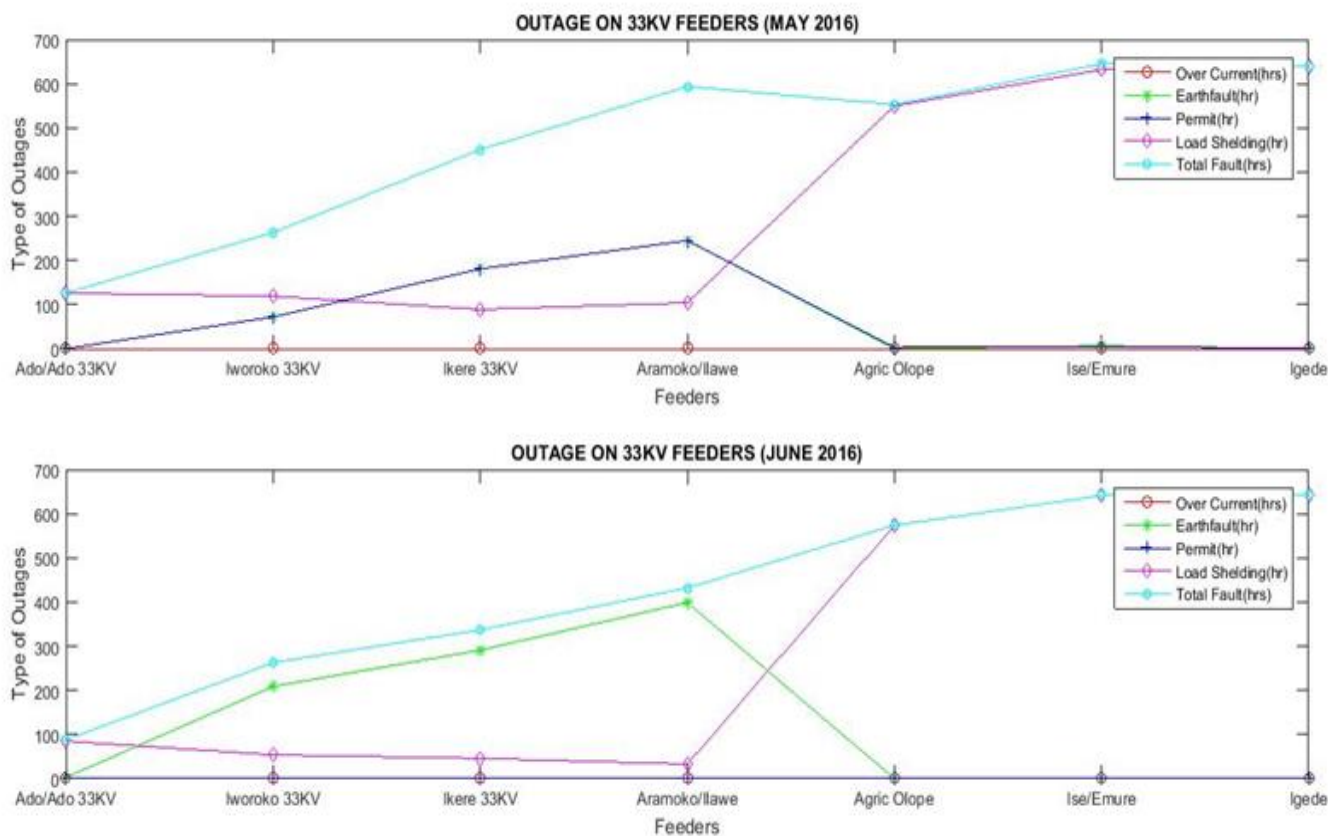

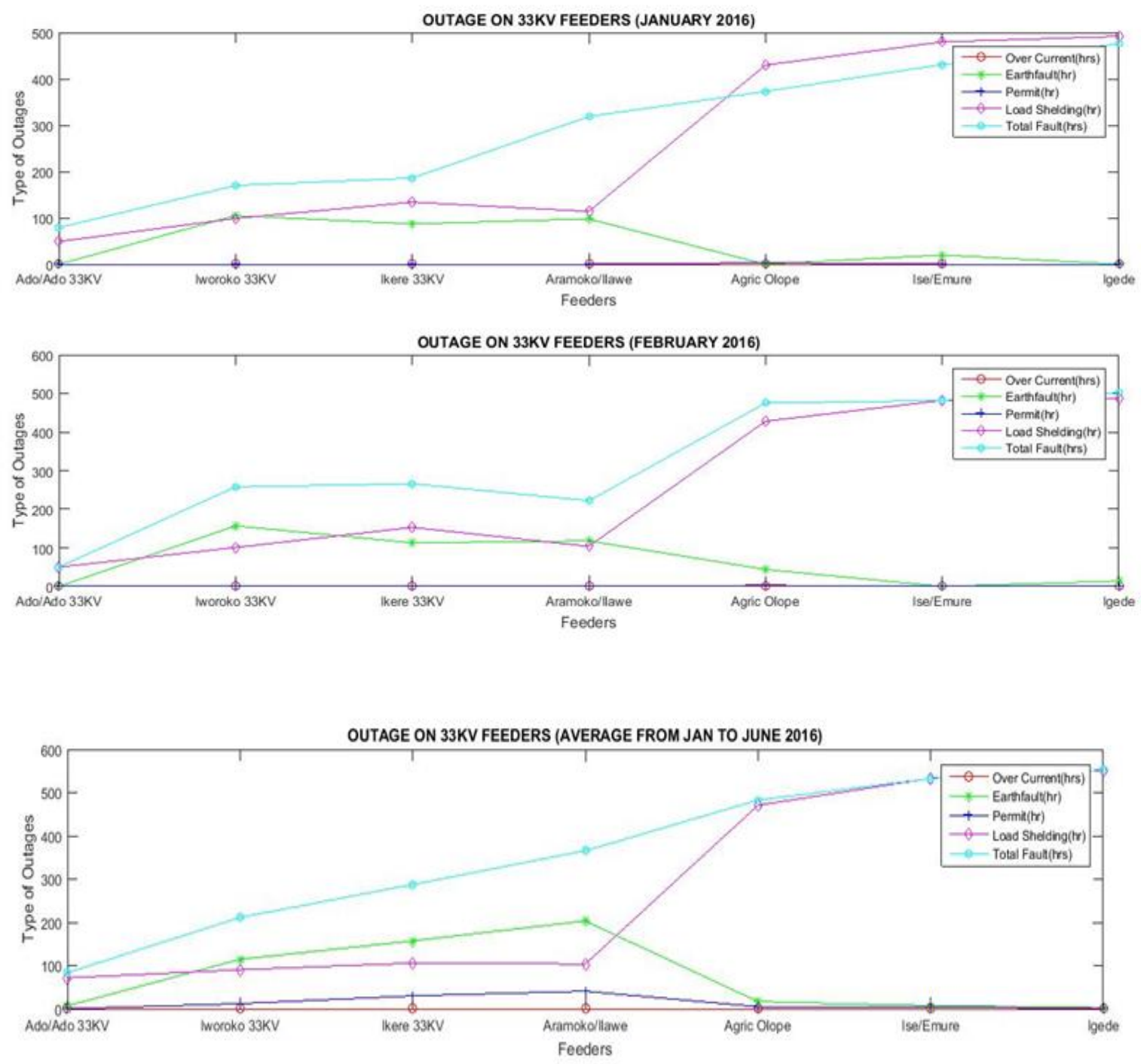

\section{Conclusion}

The level of interruption on the feeders in Ekiti State has established that the development and growth of the State is not rapid. Irregular power supply is a major contributor to slow development in the State. This has enormous effect on the artisans, the small, medium scale enterprise, farm produce and their processing. More importantly, the issues of power quality in the area of interruption have affected the quality of lives of the domestic consumers in Ekiti State adversely. It is obvious that the causes of these internal and external which are: lightning, surges, open circuits and short circuits. Earth fault is more pronounced on Ado/ Ado feeder, load-shedding is more pronounced on Aramoko feeder while permit is highly evident on Igede feeder.

\section{Recommendation}

The following recommendations were made in respect of this investigation:

- The design of power network should be re-configured with the use of adequate sizing of conductors, transformers and length.

- The network of Ekiti needs to be upgraded by the injection of higher voltage and smart grid technology.

- The causes of interruptions are: loss of supply; tree contacts; lightning; adverse weather; foreign interference and defective equipment and technical solutions should be used to eradicate or minimise them in order to meet the power demands of the Consumers.

- Cost of power supply to consumers throughout the year must outweigh the cost of not supplying power supply. 
- The technical Staff of the Disco should be proactive in clearing faults on the lines and substations in order to constantly supply power to the consumers on regularly and adequately.

\section{References}

[1] Gupta JB. A course in Power Systems, S.K Kataria and sons, Ansari Road, Darya Ganj, New Delhi. 2005; 1-377.

[2] Duze MD. Ekiti Land of Genius, Hope and Faith Press Limited, Ajilosun, Ado-Ekiti. 2005; 1-79.

[3] Melodi AO, Adeoye SA. Normal Mode Limitations of Urban and Rural Areas of Ekiti State, Nigeria, Journal of Emerging Trends in Engineering and Applied Sciences. 2013; 4(3): 485-492.

[4] Fasuan 0. Creation of Ekiti State: The epic struggle of a people, Industrial and Merchandise, Nigeria Limited, Ado-Ekiti. 2002; 1-390.

[5] SPCR. Ekiti State of Nigeria, Government PublicationAdo-Ekiti, Nigeria. 2003; 2: 1-40.

[6] Esard. Case study in Service Quality Regulation Regulation in Nigeria, NERC/ NARUC/ USAID/ MICHIGAN Public Service / Commission Twinning Committee. 2016; 1-15.

[7] Olulope PK, Adeoye OS. Investigation and Analysis of Power Quality of Single Phase, Low Voltage Consumers in Ado-Ekiti Metropolis. International Journal of Granthaalayah. 2018; 6(5): 177-189.

[8] Khalid S, Dwivedi B. Power Quality Issues, Problems, Standards and Their Effects in Industry with Corrective Means. International Journal of Advances in Engineering and Technology. 2011; 1(2): 1-11.

[9] Joseph S. The seven types of Power Problems, White Paper 18, Revision 1, APC Schneider Electric. 2001; 1-21.

[10] Barry WF. Power Quality Primer, Mc-Graw Hill Companies Incorporation. 2000; 1-385.

[11] IEEE-Std 100. IEEE Recommended Practice for Powering and Grounding Sensitive Electronic Equipment (IEE Green Book), IEEE std. 1100-1992.

[12] Rahmattahlah Pondiach, Tooraj Jamasb. Electricity Supply Interruptions. Sectoral Interdependence and the cost of Energy not served for the Scottish Economy. 2015; 1-28.

[13] Rinaldi S, Peerenboom J, Kelly T. Identifying, Understanding and Analyzing Critical Infrastructure Interdependencies, IEEE Control Systems Magazine. 2001; 11-25.

[14] Dudenhoeffer DD, Permann MR, Manic M. CIMS: A framework for infrastructure Interdependency Modeling and Analysis in Proceedings, 38th Winter Simulation Conference. December 2006; 478-85.

[15] Leahy E, Tol RSJ. An Estimate of value of lost Load for Ireland, Energy Policy. 2011; 39(3): 1514-20.

[16] Ronberg S, Bollen M. Power Quality Issues in the Electric Power System of the Future. The Electricity Journal. 2016; 29: 49-61.

[17] Miask S, Stuchly J, Vramba J, Prokop L, Uther M. Power Quality Analysis in Off-Grid Power Platform. Power Engineering and Electrical Engineering. 2017; 12(3): 177.

[18] Yagboobi J, Abdullah A, Kumar D, Zare F, Soltani H. Power Quality Issues of Distorted and Weak Distribution Networks in Minning Industry: A Review. IEEE Access. 2019; 7: 162500-162518.

[19] Mallajoshla R, Naidu IES. Power Quality Issues in Power Systems, International Journal of Innovative Technology and Exploring Engineering. 2019; 9(2S3): 308-313.

[20] Olikara K. Power Quality Issues, Impacts and Mitigation for Industrial Customers. Power and Energy Management Products, Rockwell Automation Incorporation. September 2015.

[21] Suresh M, Arup KP. Power Quality Issues and Solutions: A Review. International Journal of Emerging Electrical Power System. 2015; 16(4): 357-384.

[22] Johnson DO, Hassan KA. Issues of Power Quality in Electrical Systems. International Journal of Energy and Power Engineering. 2016; 5(4): 148-154.

[23] Horak J. Power Quality: Measurements of Sags and Interruptions. IEEE Journal. 0-7803-91934/06/420.00@2006IEEE. 2006; 1-7.

[24] Crozier JT, Wisdom WN. A Power Quality and Reliability Index Based on Consumer Interruption Costs. Power Engineering Review. 1999; 59-61. 
Global Journal of Engineering and Technology Advances, 2021, 07(03), 109-117

[25] Kufeoglu S. Economic Impacts of Elrctric Power Outages and Evaluations of Customer Interruption

Costs. Doctoral Dissertation in Permission of Aalto University, School of Electrical Engineering. 2015; 1-64.

[26] https://electrical-engineering-portal.comup-content/ uploads/2015/04/power-system- disturbances -overview retrieved on 11th February, 2018. 